\title{
Biotic Resistance of Native Communities and Alien Propagule Pressure are Consistent Predictors of Invasion Success During Grassland Establishment
}

\section{Sandra Liliana Rojas-Botero ( $\square$ sandra.rojas-botero@tum.de )}

TUM: Technische Universitat Munchen https://orcid.org/0000-0002-0366-7383

\section{Johannes Kollmann}

TUM School of Life Sciences Weihenstephan: Technische Universitat Munchen Fakultat Wissenschaftszentrum Weihenstephan fur Ernahrung Landnutzung und Umwelt

\section{Leonardo $\mathrm{H}$. Teixeira}

TUM School of Life Sciences Weihenstephan: Technische Universitat Munchen Fakultat Wissenschaftszentrum Weihenstephan fur Ernahrung Landnutzung und Umwelt

\section{Research Article}

Keywords: Biotic resistance, Competition, Ecological restoration, Environmental fluctuation, Invasibility, Priority effects, Propagule pressure

Posted Date: May 25th, 2021

DOI: https://doi.org/10.21203/rs.3.rs-423074/v1

License: (1) (i) This work is licensed under a Creative Commons Attribution 4.0 International License. Read Full License 


\section{Abstract}

Invasive alien plants challenge ecosystems restoration. Thus, understanding factors determining the establishment of invasive plants is crucial to improve restoration outcomes. Some key drivers of invasibility of plant communities have been studied, but results are inconsistent, and combined effects have not been addressed. We investigated the contribution of three drivers of invasion success during early phases of restoration, i.e., biotic resistance, invasive propagule pressure, and environmental fluctuations.

We compared the contribution of these drivers in a series of mesocosms experiments using designed grasslands as a model system, and Solidago gigantea as invasive model species. Two grassland communities were designed according to competitive trait hierarchies with different sowing patterns, reflecting variation in biotic resistance. We then manipulated invader propagule pressure and applied different scenarios of environmental fluctuation, i.e., flood, heat, and $\mathrm{N}$ fertilization. Alien biomass was considered as proxy for invasion success, while native biomass represented restoration success.

There were consistent effects of biotic resistance to $S$. gigantea invasion via competitive trait hierarchies in the three experiments. Communities dominated by species with high-competition traits were more resistant regardless of environmental fluctuation. Clumped seeding of the native community reduced invasibility, whereas larger invasive propagule size increased invasion. The effects of environmental fluctuation were less consistent and context-dependent, thus playing a secondary role when compared to biological drivers of invasion. Restoration initiatives on grasslands impacted by invasive plants should consider biotic resistance of the restored community as a key driver and the importance of controlling further arrivals of invasive species during community assembly.

\section{Introduction}

Given the well-known impacts of invasive plants on degraded ecosystems, restoration activities that constrain the spread of invasive species and promote the colonization of native ones are increasingly needed (Bakker \& Wilson 2004). However, some activities associated with restoration, e.g., clearcutting, site preparation, and topsoil removal, imply disturbances that create windows of opportunity (sensu Johnstone 1986) for further invasions (Torres et al. 2018). Thus, an emerging field in restoration ecology is the design of resident communities that are resistant to invasions during community assembly. In the case of grasslands, where the design and reintroduction of native seed mixtures is common restoration practice (Kiehl et al. 2010), most evidence shows that revegetation can decrease the performance of invasive plants, although the magnitude of such effect is variable (Schuster et al. 2018). Since biotic resistance is only one aspect explaining to what extent invasion can succeed, other invasion drivers need to be considered as well, i.e., invasive propagule pressure and time of arrival of the invasive species, and the influence of environmental constraints (Byun et al. 2015). 
The biotic resistance of a resident community implies a reduction of invasibility mainly through competition (Levine et al. 2004). Although there is little evidence of species interactions being able to repel invaders completely, some resident communities can constraint the establishment, abundance, and fitness of invaders to a certain extent (Levine et al. 2004). The understanding of biotic resistance as driven by interspecific competitive interactions has been addressed by various hypotheses, based on diversity effects and the saturation of niche space (Elton 1958; Hooper et al. 2005), limiting trait similarity (Funk et al. 2008), phylogenetic relatedness (Yannelli et al. 2017b), or trait hierarchies, with the focus on the identity and value of fitness-related traits defining what species are more likely to successfully invade (Kunstler et al. 2012).

An additional mechanism to increase biotic resistance and diminish invasion success in early community assembly is the management of community density (Yannelli et al. 2018). Threshold seed densities and sowing patterns can play an important role in invader suppression in newly restored ecosystems (Reinhardt Adams \& Galatowitsch 2007) by increasing competition for light (Lindig-Cisneros \& Zedler 2002) and, thus, reducing the establishment of invaders even when arriving at higher densities (Byun et al. 2015). In turn, the propagule pressure of invasive plants is a key determinant of invasion success (Von Holle \& Simberloff 2005; Simberloff 2009). It comprises the number of individuals in a propagule ('propagule size'), and the rate at which propagules arrive per unit of time ('propagule number'; Lockwood et al. 2005). Previous studies acknowledge propagule pressure as a key factor explaining invasion success, thus the minimization of propagule pressure, along with rapid revegetation, is thought to reduce the impact of invasive plants in areas undergoing restoration (Colautti et al. 2006; Hufbauer et al. 2013; Cassey et al. 2018).

Moreover, abiotic constraints and environmental variability significantly interact with biological invasions. Harsh abiotic constraints can affect the performance of invasive and native species (Melbourne et al. 2007; Parepa et al. 2013), and thus influence invasion outcomes (Going et al. 2009). Since invasive species can capitalize on greater resource availability after a disturbance or reduced competition, climatechange effects are thought to increase the establishment of invasive species (Sorte et al. 2013; Funk et al. 2020). Abiotic fluctuations such as flood (Gerhardt \& Collinge 2003; Collinge et al. 2011), soil fertilization (Goldstein \& Suding 2014), or extreme climatic effects (Collinge et al. 2011; Goldstein \& Suding 2014) play a decisive role in invasibility, and therefore need more experimental studies, especially when the likelihood and frequency of heatwaves, floods, and droughts increase with climate change (Kam et al. 2018; Knutson et al. 2018; Schiermeier 2018).

While the importance of trait similarity and phylogenetic relatedness on community invasibility is ambiguous (Byun et al. 2015; Funk \& Wolf 2016; Yannelli et al. 2017c; Byun et al. 2020), the effects of environmental stress (Conti et al. 2018), trait hierarchies (Funk \& Wolf 2016; Carmona et al. 2019), and seed density (Yannelli et al. 2017a; Yannelli et al. 2018; Byun et al. 2020) are increasingly supported as suitable proxies of competition outcomes, and thus of the biotic resistance of a plant community. However, interactions of trait hierarchies and environmental fluctuations with propagule pressure and 
priority effects (i.e., time of arrival of the species) need further research to elucidate their relative effect, and hence to improve ecological restoration under climate change.

In this study, we investigate specific and combined effects of the following drivers of the successful establishment of invasive plants during early phases of community assembly in experimental grassland communities: (i) biotic resistance via competitive trait hierarchies and (ii) via seed clumping of the resident community, (iii) propagule pressure of the invasive species, and (iv) abiotic constraints. We applied the concept of trait hierarchies by designing two native communities a priori, in which species abundances were manipulated to obtain one grassland dominated by highly competitive species, and another one dominated by low-competitive ones. On these communities, the effect of seed clumping, propagule pressure, and abiotic constraints was experimentally tested to answer the following questions: (1) Is a reduced invasibility attributable to the biotic resistance attained via trait hierarchies within the native resident community? (2) What is the role of seed clumping of the native species on the establishment of the invasive species? (3) To what extent do propagule size or propagule number affect invasion success? (4) Do environmental fluctuation increase grassland invasibility? (5) Are there cascading effects between biotic resistance, propagule pressure, and the abiotic constraints, that favor grassland invasion?

\section{Materials And Methods}

\section{Study system}

We assessed invasion success in three mesocosm experiments: one in a greenhouse and two in climate chambers. Semi-natural mesic grasslands of Central Europe were the model system in which we investigated the relative importance of different drivers on the invasion success of Solidago gigantea Aiton (Asteraceae), a common invasive forb from North America, that was introduced as an ornamental to Europe in the 18th century (Weber \& Jakobs 2005).

The experiments simulated early phases of active restoration of grasslands, in which particular mixtures of native species are sown on bare soil (Kiehl et al. 2010), while seeds of S. gigantea concomitantly arrived. Trait hierarchies, sowing patterns, propagule pressure of the invasive species, and environmental fluctuations were manipulated to assess the ability of the resident communities to hinder invasion. Environmental fluctuation scenarios consisted of manipulations of $\mathrm{N}$ fertilization in the greenhouse experiment, and heat and flood experiments in climate chambers.

\section{Design of native communities}

Two community types were established for testing biotic resistance as a function of fitness-related trait hierarchies of the study species. For this, five native grass species were selected and allocated in the trait hierarchy based on their ecological indicator values for nutrients (EIV-N) (Ellenberg 1974). EIV-N values positively correlated to fitness-determining traits (e.g., seed mass, relative growth rate, specific leaf area) and thus they are good proxies for ecophysiological characterization of the native species, especially 
during establishment (Bartelheimer \& Poschlod 2016). The resulting hierarchy was Arrhenatherum elatius (L.) P.Beauv. ex J.Presl \& C.Presl. > Holcus lanatus L. > Dactylis glomerata L. > Festuca rubra L. > Festuca ovina L. Experimental grassland communities composed of native grasses were chosen because this functional group generates high biotic resistance to invasions, compared to other growth forms (Sheley \& James 2010; Török et al. 2010), and rapidly colonizes open areas (Young et al. 2009).

The two grassland types were designed based on the relative abundances of the native grasses constituting both communities. In community ARR50, the species with the highest competitive ability was more abundant (A. elatius dominating), whereas, in community ARR5, species with a lower competitive ability were more abundant ( $F$. ovina dominating; Table 1 ). For all experiments, $3 \mathrm{~g} \mathrm{~m}^{-2}$ was set as target sowing density, mimicking recommendations in grassland revegetation (Kiehl et al. 2010). The effective density of the seeds needed for ARR5 and ARR50 was based on seed mass, adjusted considering the $a$ priori germination rates tested for each species (Table S1).

Table 1. Composition of the two community types of resident grasslands tested in our experiments. Community ARR50 had a higher abundance of high-competition species, while ARR5 was dominated by less competitive species.

\begin{tabular}{|lll|}
\hline Grass species & ARR50 & ARR5 \\
\cline { 2 - 3 } & (\%) & (\%) \\
\hline Arrhenatherum elatius & 50 & 5 \\
\hline Holcus lanatus & 25 & 8 \\
\hline Dactylis glomerata & 12 & 12 \\
\hline Festuca rubra & 8 & 25 \\
\hline Festuca ovina & 5 & 50 \\
\hline
\end{tabular}

Trait-hierarchy, sowing-pattern and $\mathrm{N}$-fertilization experiment

To test for the effect of competitive trait hierarchy ('community type') and seed clumping as the expression of biotic resistance in combination with abiotic constraints, a greenhouse experiment was conducted for 18 weeks. Forty plastic trays $\left(48.2 \times 33 \times 6.2 \mathrm{~cm}^{3}\right.$, i.e., $0.16 \mathrm{~m}^{2}$ area and $0.0098 \mathrm{~m}^{3}$ volume each) were filled with two parts of potting soil and one part of vermiculite and distributed in five blocks. Each tray was split into two halves by polystyrene pieces of $33.0 \times 6.2 \mathrm{~cm}^{2}$ allowing for a split-plot design. Each whole tray contained a combination of community type, seeding pattern, and $\mathrm{N}$ fertilization, resulting in four possible treatment combinations and five replicates per treatment combination (Fig. S1.1). 
Half of the trays contained community ARR5 and the other half ARR50. In the 'random' treatment, the native mixture was spread over the entire tray; in the 'clumped' treatment, the same amount of seed mixture was sown in $59 \%$ of the area by applying seeds in a concentric pattern to simulate clumped establishment of the plant communities, while $31 \%$ of the area was left open (Fig. S1.2). Solidago gigantea was sown simultaneously with the native mixture with $1 \mathrm{~g} \mathrm{~m}^{-2}$ in one half of each tray, while the second half was uninvaded.

To test the influence of $\mathrm{N}$-fertilization on the competitive outcome of native and invasive species, we applied fertilizer in two different levels at the early stages of community establishment. Half of the trays received only a basic amount of NPK (Peters Excel Grower 15/5/15, $100 \mathrm{~g} / 100 \mathrm{I}$ ), while the second half received additional nitrogen (Novatec 18 Fluid, $85 \mathrm{~g} / 100 \mathrm{I}$ ). Fertilization was done once a week by watering $1 \mathrm{I}$ of dissolved nutrients; in total, $0.6 \mathrm{~g} \mathrm{~N}$ together with $\mathrm{P}$ and $\mathrm{K}$ were added to provide a basic nutrition supply. An extra supply of $0.6 \mathrm{~g} \mathrm{~N}$ simulated fluctuating fertilization. The $\mathrm{N}$ fertilization levels were equivalent to 37.5 or $75.0 \mathrm{~kg} \mathrm{~N} \mathrm{ha}^{-1}$, representing low- and high-intensity grasslands, respectively (Vitousek et al. 1997; Butterbach-Bahl et al. 2011). No extra water was added during the enrichment period, to keep soil moisture levels similar. Afterward, tap water was added 1-3 times per week, depending on the growth stage of the mesocosms and temperatures inside the greenhouse.

After 16 weeks, the aboveground biomass of the invasive species and the native community was harvested $1 \mathrm{~cm}$ above the soil level, and the biomass was oven-dried at $65^{\circ} \mathrm{C}$ for $48 \mathrm{~h}$ and weighed.

\section{Trait-hierarchy and heat-flood pulse experiment}

To test for the effect of community type in combination with heat and flood pulses, an experiment was conducted in two walk-in climate chambers $\left(2.4 \times 3.2 \times 2.2 \mathrm{~m}^{3}\right.$; area $7.7 \mathrm{~m}^{2}$; Fig. S1.3) at TUMmesa (TUM Model EcoSystem Analyser) at Technical University of Munich (Roy et al. 2021). During the experiment, the chambers were maintained at $12 \mathrm{~h}$ light and $12 \mathrm{~h}$ dark, air temperature was set to $25 / 15^{\circ} \mathrm{C}$ (day/night range), and 60-65\% relative humidity. Air $\mathrm{O}_{3}$ concentration was constant at $0.58 \mathrm{ppb}$, while $\mathrm{CO}_{2}$ varied between 380-450 ppm. Commercial sterilized potting soil (Floradur® Pot substrate) was placed in 48 trays of the above-mentioned size. Each tray was again split into two halves, allowing for a split-plot design. The trays were placed on standard greenhouse floodable tables with six trays per table and four tables per chamber (Fig. S1.4 and S1.5).

In each of the floodable tables, three trays per community type (ARR5 and ARR50) were randomly allocated, and the position within each table was biweekly re-randomized. S. gigantea was simultaneously sown with the native mixture in a density of $1 \mathrm{~g} \mathrm{~m}^{-2}$ in one-half of each tray, the second half was not sown with the invasive species. Water was supplied to the plants every second day, by pouring 10 I of tap water directly in the table, enabling water uptake by the roots. To assess the effect of heat and flood pulses, the experimental communities were subjected to interspersed simulated temperature increases and floods after the third week since start of the experiment. For this, one chamber was randomly selected and its temperature increased from $25 / 15^{\circ} \mathrm{C}$ to $35 / 20^{\circ} \mathrm{C}$ for $48 \mathrm{~h}$ every second 
week. To simulate the flood events, two tables per chamber were randomly selected and watered with $50 \mathrm{I}$ of tap water and maintained flooded for $48 \mathrm{~h}$ every two weeks.

To measure the competitive outcome of the communities under such environmental fluctuations, the aboveground biomass of the invasive species and the native community was harvested $1 \mathrm{~cm}$ above the soil level after 14 weeks of community development; it was oven-dried at $65^{\circ} \mathrm{C}$ for $48 \mathrm{~h}$ and weighed.

\section{Trait-hierarchy, propagule-pressure and heat-flood experiment}

To assess the role of propagule pressure in combination with heat and flood pulses on the biotic resistance of the communities, a similar experimental approach was tested in four climate chambers of TUMmesa. The two community types were subjected to competition with the invasive given three levels of propagule pressure: (i) One single introduction, simultaneously with the sowing of the native seeds, with a density of $1 \mathrm{~g} \mathrm{~m}^{-2}$; (ii) three biweekly introductions, each of them with a density of $1 \mathrm{~g} \mathrm{~m}^{-2}$; and (iii) one single introduction, with a density of $3 \mathrm{~g} \mathrm{~m}^{-2}$, simultaneously with the sowing of the native mixture. The experiment was carried out with three fully crossed factors: community type, propagule pressure, and environmental fluctuation (i.e., extreme heat and floods).

In each chamber, two tables contained trays with the community ARR50 and two tables ARR5. Each of the 96 trays was split into two halves. By using the split-plot approach of the trays, each treatment combination had a corresponding control at the side, i.e., with no addition of $S$. gigantea seeds. The three propagule pressure levels were randomly applied in each half of the 96 trays, so in each table, each propagule level was applied in two half-trays (Fig. S1.6). Whenever not submitted to flooding, water was supplied to the plants every second day, by pouring 10 I of tap water into the table.

To assess the effect of environmental fluctuations, two of the chambers were randomly selected to simulate six interspersed heat pulses and floods after the third week of community development under the conditions described in the previous experiment. To simulate extreme heat pulses, the temperature was increased from $25^{\circ} \mathrm{C}$ to $35^{\circ} \mathrm{C}$ for $72 \mathrm{~h}$ every second week. To simulate six flood events, two tables per chamber corresponding to two different treatment combinations were randomly selected and supplied with $50 \mathrm{I}$ of tap water and maintained flooded for $72 \mathrm{~h}$ every two weeks.

After 17 weeks, the aboveground biomass was harvested by clipping the shoots $1 \mathrm{~cm}$ above the soil level; the material was dried at $65^{\circ} \mathrm{C}$ for $96 \mathrm{~h}$ and weighed. Aboveground biomass of the plants was considered appropriated to relate to the biotic resistance of the native species, and the invasion success in the treatments applied.

\section{Data analyses}

To test the effect of each driver, i.e., biotic resistance (two levels of trait hierarchy), sowing pattern of resident communities, propagule pressure of the invasive species (three levels), and environmental fluctuations ( $\mathrm{N}$-fertilization, heat waves, and flood pulses, with two levels each), linear mixed-effects 
models (LMMs) with random intercepts were fitted using the function Ime from the R package nlme (version 3.1.137) (Pinheiro et al. 2021). Experimental blocks or climate chambers and experimental tables were defined as random effects accordingly, whereas biomass of the native community, competitive hierarchy, sowing pattern, propagule pressure, heat waves, and flood pulses, were included as fixed effects explaining biomass of $S$. gigantea in the respective experiments. Assumptions of normality of residuals and homoscedasticity were checked using model plots. The response variable 'aboveground biomass' was log-transformed to meet the assumption of a normal distribution of residuals whenever needed. To account for cases of non-homogeneity of variances, we used a variance structure (Varldent) for the propagule level (Experiment 3).

Since the trait hierarchies, sowing pattern, propagule pressure, and abiotic conditions were expected to have complex direct and indirect effects on the resulting biomass of native and invasive plants, confirmatory path analyses (i.e., piecewise Structural Equation Models, SEM) were applied to assess the causal relationships depicting them. Piecewise SEM combines information from multiple separated models into a single causal network (Shipley 2009). Moreover, because the individual models used for piecewise SEM included random effects and did not always have a normal distribution, piecewise SEM was advantageous to conduct SEM analyses (Lefcheck \& Duffy 2015). For each experiment, a single causal network relating to the paths of interest was constructed. Since the a priori models were saturated, i.e., all possible paths were considered, no overall goodness-of-fit based on the test of directed separation (Shipley 2000) is provided (here Fischer's $C=0$, with p-value $=1$ ). Marginal model fit $\left(R^{2}\right)$ of individual path models ranged from $19 \%$ to $91 \%$ of variance explained (Figure 4 ). We assessed the relative importance of the variables included in the final SEMs using standardized path coefficients scaled by mean and variance. LMMs using the package NLME (Pinheiro et al. 2016) were the base for fitting the SEM in the package piecewiseSEM version 2.0.2 (Lefcheck 2016).

\section{Results}

\section{Effects of trait-hierarchy, sowing-pattern and $\mathrm{N}$-fertilization}

Grass communities dominated by high-competition species had a more negative effect on the biomass production of the invasive $S$. gigantea (mean \pm SE: ARR50: $0.45 \pm 0.08 \mathrm{~g}$ vs. ARR5: $1.00 \pm 0.17 \mathrm{~g}$; Fig. 1 , Table S3). Also, sowing patterns had a significant effect on the biomass production of the invasive species. Clumping led to a direct increase per unit area of native biomass production (clumped: $50.0 \pm 1.3$ $\mathrm{g}$ vs. random: $43.5 \pm 1.3 \mathrm{~g}$ ). An increased input of nitrogen did not stimulate the biomass of the invasive species. Instead, it favored the biomass of the native community ( $\mathrm{N}$-enriched: $54.9 \pm 1.3 \mathrm{~g}$ vs. Nonenriched: $38.6 \pm 1.3 \mathrm{~g}$ ), which might result in negative effects on invasive biomass (Fig. 1). The total community biomass, i.e., the biomass of native and invasive species added up, was overall positively affected by $\mathrm{N}$-enrichment $(\mathrm{p}<0.001)$ and a clumped sowing $(\mathrm{p}<0.001$; Fig. S2.1, Table S2). 
Similar to previous results, there were negative effects of the high-competition community on the biomass of the invasive species (ARR50: $5.42 \pm 0.67 \mathrm{~g}$ vs. ARR5: $9.45 \pm 0.70 \mathrm{~g}$; mean \pm SE) (Fig. 2, Table S3). Moreover, environmental fluctuation (interspersed flood pulses and heat) had a positive effect on the biomass of the native community (Fig. 2). The total community biomass was significantly higher in invaded communities $(p<0.001)$, and positively affected by flood and heat pulses $(p<0.001)$, with ARR50 being less productive $(p<0.005)$ (Fig. S2.2, Table S3).

\section{Effects of trait-hierarchy, propagule-pressure and heat-flood pulses}

We found strong evidence of biotic resistance conferred by trait hierarchies also when the propagule pressure of the invasive species was manipulated, in addition to environmental fluctuations. The community dominated by high-competition species had a negative effect on the biomass of the invasive species (ARR50: $1.00 \pm 0.17 \mathrm{~g}$ vs. ARR5: $1.53 \pm 0.17 \mathrm{~g}$ ) (Fig. 3, Table S3). Flooding did not affect the biomass of either native or invasive plants (Fig. $3 \mathrm{~A}$ ). In contrast to the previous experiment, heat had a positive effect on the invasive biomass (heat: $1.45 \pm 0.17 \mathrm{~g}$ vs. non-heat: $1.08 \pm 0.17 \mathrm{~g}$; Fig. 3B). Added early in the assembly process a large-sized propagule of $S$. gigantea had a negative effect on native biomass and increased biomass of the invasive species (Fig. 3). A large-sized propagule of the invasive species led to highest invasive biomass (3: $2.79 \pm 0.42 \mathrm{~g}$ vs. $1: 0.52 \pm 0.10 \mathrm{~g})$. Contrastingly, three propagule introductions were not different to single seeding (1: $0.52 \pm 0.10 \mathrm{~g} 1+1+1: 0.48 \pm 0.08 \mathrm{~g})$ (Fig. $3)$. The total community biomass was only significantly higher in invaded communities $(p=0.005)$ (Fig. S2.3, Table S2).

\section{Direct and indirect drivers of plant invasion}

The structural equation models indicated that the high-competition communities were more resistant against the invasive species irrespective of environmental fluctuations (Fig. 4a-c). While clumped sowing and high competition traits of the grass communities were positive for native biomass, environmental drivers positively affected native and invasive biomass in the first and second experiment, respectively (Fig. 4a, b). In contrast, no effects of environmental drivers were observed in the third experiment (Fig. 4c).

In the first experiment, native biomass was positively affected by clumped sowing (estimate $=0.32, p \leq$ 0.001 ) and $N$ enrichment (estimate $=0.80, p \leq 0.001$ ), with indirect negative effects on invasive biomass (Fig. 4a). Thus, native biomass exerted a negative control over invasive biomass (estimate $=-0.59, \mathrm{p} \leq$ 0.05). Together with the effects of native biomass, trait hierarchy also negatively affected invasive biomass (estimate $=-0.44, p \leq 0.01$, Fig. $4 a$ ). In the second experiment, native biomass was positively affected by environmental fluctuations (estimate $=0.55, p \leq 0.001$ for heat; estimate $=0.51, p \leq 0.001$ for flood). However, no influence of native biomass on invasion was observed (Fig. 4b). This time, communities dominated by highly competitive plants were positively affecting native biomass (estimate $=0.27, p \leq 0.05$ ), while again suppressing invasion (estimate $=-0.46, p \leq 0.001$ ). Finally, flood pulses positively affected invasive biomass (estimate $=0.58, p \leq 0.001$ ), indicating that, depending on the scenario, environmental drivers can also facilitate invasion (Fig. 4b). In the third experiment, invasive 
propagule pressure positively controlled invasive biomass (estimate $=7.58, p \leq 0.001$ ), while native biomass was negatively affected (estimate $=-0.20, p \leq 0.05$ ). Once more, the more competitive community had a lower invasive biomass (estimate $=-0.12, p \leq 0.05$ ). However, due to a stronger effect of invasive propagule pressure on native and invasive biomasses, this effect was almost four times smaller than what was previously observed (Fig. 4c).

\section{Discussion}

\section{Biotic resistance in early stages of grasslands}

In all three experiments, the effect of the biotic resistance derived from trait hierarchies led to a reduction in biomass on the invasive species during the establishment of synthetic grassland communities, irrespective of environmental fluctuations in nutrients, water and temperature, and for every level of invasive propagule pressure. This result supports the hypothesis of biotic resistance attained by competitive hierarchies based on the identity and value of fitness-related functional traits (Laughlin 2014; Funk \& Wolf 2016; Conti et al. 2018; Carmona et al. 2019; Ferenc \& Sheppard 2020). Moreover, it agrees with the mass ratio theory (Grime 1998), posing that the effects of a certain community on competition are driven by the traits of the dominant species. This explains why the high-competition community ARR50 was more efficient in suppressing $S$. gigantea in the three experiments.

\section{Sowing patterns and invasibility}

The pattern of seed sowing showed that clumping, and thus locally higher densities both of the invasive species and the native grass community, reduced the biomass of $S$. gigantea. By sowing in circular clumps within the experimental trays, the plasticity of plant growth may have allowed the roots of the native grasses to rapidly forage the surrounding un-vegetated areas of high (soil) resource levels. Similar mechanisms were suggested by Fargione et al. (2003), Török et al. (2010), and Lu et al. (2020). The resulting growth rate advantage of the native grasses led to stronger asymmetric (aboveground) competition (Freckleton \& Watkinson 2001; Weiner et al. 2001), and thus enhanced suppression of $S$. gigantea.

Additionally, the clumped sowing pattern in our experiment generated a local-scale increase in density of the native community. The negative effects on invasive biomass due to this higher local density implies that the competition for light benefitted the native plants (Weiner et al. 2001; Lindig-Cisneros \& Zedler 2002; Nemec et al. 2013; Byun et al. 2015; Yannelli et al. 2018; Byun et al. 2020), especially in the community ARR50, whose dominant species were able to grow rapidly, to fill the available space, and to create a dense canopy (Colbach et al. 2014). This result underpins the importance of rapid and uniform occupancy of space combined with higher density and highly productive species to suppress unwanted species (Hess et al. 2020; Lu et al. 2020). However, even though clumped seeding reduced S. gigantea invasion, in a real-world setup of bare ground revegetation, gaps between clumps must be reduced to minimize invasibility of the community (Lu et al. 2020). 
Our study published evidence on the importance of propagule pressure for invasion success (Simberloff 2009; Byun et al. 2015; Byun et al. 2020). A large propagule size (i.e., high seed density) in the early stages (i.e., priority effect) of colonization of bare soil resulted in the highest aboveground biomass of $S$. gigantea, and thus most successful establishment of the invasive species (Hess et al. 2019). Priority effects were identified as key factor explaining the assembly of communities, together with trait-based assembly rules (Fukami et al. 2005). Since resources (e.g., space, nutrients, light) are fully available at very early phases of colonization, most of the propagule of $S$. gigantea rapidly pre-empted or modified the available niche (cf. Fukami 2015) with negative effects on the native species (Dickson et al. 2012). Furthermore, our results also suggest propagule size, and not propagule number as a stronger determinant of the invasion success in S. gigantea.

This finding further supports the importance of priority effects for invasion resistance (Gillhaussen et al. 2014; Viana et al. 2016; Hess et al. 2019; Yannelli et al. 2020; Weidlich et al. 2021). The strikingly lower biomass production of $S$. gigantea when introduced in three pulses of $1 \mathrm{~g} \mathrm{~m}^{-2}$ each compared to a single event of $3 \mathrm{~g} \mathrm{~m}^{-2}$ suggest a marked priority effect of the resident community (Hess et al. 2020), capturing resources and thus, limiting the establishment of S. gigantea. As stated by Simberloff (2009), propagule number becomes more important if it interplays with demographic or environmental stochasticity, and has a notable effect when a large number of introduction events triggers the establishment of the invasive species. Notwithstanding, regardless of the propagule pressure, the community ARR50 was negatively affecting invasion success, since competitive hierarchies offset priority effects to a high degree. Thus, arrival order and propagule size are less important when highly competitive native species are present in the invaded community (Fukami 2015).

\section{The role of abiotic fluctuations}

In our experiments, we applied environmental fluctuations as pulse events following Jentsch \& White (2019), i.e., some system resources or abiotic factors were abruptly modified to test their effects on grassland invasibility. Native communities capitalized on pulses of nitrogen supply, especially ARR50, and prevented the invasive species from taking advantage of extra nitrogen availability, given the dominance of highly competitive native species (Walker et al. 2015; Conradi et al. 2017; Liu et al. 2018). Despite $S$. gigantea growing best in nitrogen-rich habitats (Weber \& Jakobs 2005), and invasive species, in general, responding faster to environmental fluctuations (Davis et al. 2000; Liu \& Kleunen 2017; Liu et al. 2019) and enhancing nutrient uptake (Dassonville et al. 2008; Liu et al. 2019), our experiment did not show advantages for invasion of $S$. gigantea with a pulsed supply of nitrogen in our model systems, that represent early stages of grassland establishment. This might be different in later stages where $S$. gigantea with rapid resource exploitation, high growth rates, a tall and dense canopy, and clonal propagation could dominate disturbed grasslands (Weber \& Jakobs 2005). 
Thus, with the duration of the environmental fluctuations simulated in our experiments, we detected no clear benefits for the invader, suggesting that environmental fluctuations need broader testing, e.g., accounting also for different magnitudes and temporal patterns of resource or environmental pulses of flood and heatwaves (Parepa et al. 2013; Koerner et al. 2015; Matsubara \& Sakai 2016). This way, the fluctuating conditions depicting the superior ability of the invasive plants to capitalize on periods of high resource availability (rapid response or higher maximum growth rate) can be better identified.

\section{Cascading effects on plant invasions}

Our study revealed that designing resident grassland communities based on trait hierarchies has a consistent direct effect on the biomass of the invasive species during early stages of community assembly, even when other invasibility drivers are at stake. Moreover, clumped sowing patterns increased the asymmetry of competition in favor of the native communities, improved their productivity, and thereby indirectly affected the productivity of the invasive species. Conversely, we found that the large propagule size of S. gigantea in the third experiment influenced the establishment of that species in two ways: On the one hand, a large propagule of the invasive established first, and quickly produced a canopy to capitalize on the available resources, thus having a direct negative effect on the biomass production of the native species. On the other hand, a large propagule size (i.e., density), promoted a greater biomass production of the invasive species (Byun et al. 2015), while the biomass of the native community was not consistently mediating negative effects on the invasive biomass across the experiments. In the invaded communities, the biomass production of communities was not always different, yet the community ARR50 was always more effective in decreasing the biomass of $S$. gigantea.

The suppression mechanism on the invasive species may be therefore related not only to higher resource capture but to the expression of other competition traits (Yannelli et al. 2020). Only when there was a pulsed, extra supply of nitrogen and a clumped sowing pattern, the performance of ARR50 disproportionally increased its biomass production, with a negative effect on the biomass of S. gigantea. In contrast to common expectations (Hood \& Naiman 2000; Kercher \& Zedler 2004; Collinge et al. 2011; Goldstein \& Suding 2014), the fluctuation in physical parameters (heat and flood pulses) did not have a consistent effect on the performance of the native community nor the productivity of the invasive species in the two experiments that tested for it, suggesting that even small differences in magnitude or frequency of pulsed environmental fluctuations can have significantly different outcomes in competition between native communities and invasive species.

\section{Conclusions}

In this study, we aimed at understanding specific and combined effects of known drivers of alien plant invasions. We showed that biotic resistance based on hierarchies of traits related to competition has a consistent effect on invasion outcomes. Plant communities dominated by strong competitors can reduce invasibility by limiting the productivity of invasive plants. The propagule pressure of the invasive species plays a substantial role when large sizes of a propagule arrive early in the assembly process stressing the 
importance of priority effects. The environmental fluctuations, in contrast, were an inconsistent predictor of invasion outcomes, suggesting context-dependent effects. Previous studies have confirmed how different drivers such as seed provenance, prior arrival of invasive species, and light fluctuations can also contribute to invasion outcomes. This calls for the need of conducting follow-up studies combining also these drivers in more complex setups. However, our results suggest that revegetation or restoration practice needs to account for biotic resistance of the restored community and also the importance of controlling the further arrival of invasive species to limit their effect in early phases, e.g increasing seed clumping rates.

\section{Declarations}

Funding: SR-B conducted her research in the frame of the joint project LandKlif, funded by the Bavarian Ministry of Science and the Arts via the Bavarian Climate Research Network (bayklif; F.7F5121.14.2.3/14/9) and DFG (INST 95/1184- FUGG) establishing TUMmesa.

Conflicts of interest/Competing interests: The authors have no conflicts of interest.

Data availability: All data included in this manuscript will be made available via MediaTUM.

Author's contribution: LHT and JK conceived and designed the experiments; SRB and LHT conducted the experiments; SR and LHT collected, analyzed, and interpreted the data; SR and LHT led the writing and editing of the manuscript. All authors contributed critically to the drafts and gave final approval for publication.

\section{ACKNOWLEDGEMENTS}

We appreciate the contributions of Holger Paetsch, Jie Si Ma, Robin Fahle, Andrea Frank, and Johannes Prifling during the experimental development of the study and the pre-processing of data. The staff at Greenhouse Laboratory Center Dürnast provided continuous technical support during the experiments. The technical and scientific staff at the TUMmesa facility contributed to the implementation of the experiments. Funding for conducting the research was provided by DFG (INST 95/1184- FUGG) the LandKlif Project by StMWK (F.7-F5121.14.2.3/14/9). We would like to thank all reviewers for their valuable comments and important contribution to improving this manuscript.

\section{References}

Bakker JD, Wilson SD (2004) Using ecological restoration to constrain biological invasion. Journal of Applied Ecology 41:1058-1064. doi: 10.1111/j.0021-8901.2004.00962.x

Bartelheimer M, Poschlod P (2016) Functional characterizations of Ellenberg indicator values - a review on ecophysiological determinants. Functional Ecology 30:506-516. doi: 10.1111/1365-2435.12531 
Butterbach-Bahl K, Gundersen P, Ambus P, Augustin J, Beier C, Boeckx P, Dannenmann M, Gimeno BS, Ibrom A, Kiese R, Kitzler B, Rees RM, Smith KA, Stevens C, Vesala T, Zechmeister-Boltenstern S (2011) Nitrogen processes in terrestrial ecosystems. Pages 99-125. In: Sutton MA, Howard CM, Erisman JW, Billen G, Bleeker A, Grennfelt P, van Grinsven H, Grizzetti B (eds) The European Nitrogen Assessment. Cambridge University Press, Cambridge

Byun C, Blois S de, Brisson J (2015) Interactions between abiotic constraint, propagule pressure, and biotic resistance regulate plant invasion. Oecologia 178:285-296. doi: 10.1007/s00442-014-3188-z

Byun C, Oh M, Lee EJ, Kang H (2020) Seed density is as important as limiting similarity, diversity effect, and propagule pressure in plant restoration to control invasion. Ecological Engineering 144:105712. doi: 10.1016/j.ecoleng.2019.105712

Carmona CP, Bello F, Azcárate FM, Mason NWH, Peco B (2019) Trait hierarchies and intraspecific variability drive competitive interactions in Mediterranean annual plants. Journal of Ecology 107:20782089. doi: 10.1111/1365-2745.13248

Cassey P, Delean S, Lockwood JL, Sadowski JS, Blackburn TM (2018) Dissecting the null model for biological invasions: A meta-analysis of the propagule pressure effect. PLoS Biology 16:e2005987. doi: 10.1371/journal.pbio.2005987

Colautti RI, Grigorovich IA, Maclsaac HJ (2006) Propagule pressure: A null model for biological invasions. Biological Invasions 8:1023-1037. doi: 10.1007/s10530-005-3735-y

Colbach N, Collard A, Guyot SHM, Mézière D, Munier-Jolain N (2014) Assessing innovative sowing patterns for integrated weed management with a 3D crop:weed competition model. European Journal of Agronomy 53:74-89. doi: 10.1016/j.eja.2013.09.019

Collinge SK, Ray C, Gerhardt F (2011) Long-term dynamics of biotic and abiotic resistance to exotic species invasion in restored vernal pool plant communities. Ecological applications : a publication of the Ecological Society of America 21:2105-2118. doi: 10.1890/10-1094.1

Conradi T, Temperton VM, Kollmann J (2017) Resource availability determines the importance of nichebased versus stochastic community assembly in grasslands. Oikos 126:1134-1141. doi:

10.1111/oik.03969

Conti L, Block S, Parepa M, Münkemüller T, Thuiller W, Acosta ATR, van Kleunen M, Dullinger S, Essl F, Dullinger I, Moser D, Klonner G, Bossdorf O, Carboni M (2018) Functional trait differences and trait plasticity mediate biotic resistance to potential plant invaders. Journal of Ecology 106:1607-1620. doi: $10.1111 / 1365-2745.12928$

Dassonville N, Vanderhoeven S, Vanparys V, Hayez M, Gruber W, Meerts P (2008) Impacts of alien invasive plants on soil nutrients are correlated with initial site conditions in NW Europe. Oecologia 
Davis MA, Grime JP, Thompson K (2000) Fluctuating resources in plant communities: a general theory of invasibility. Journal of Ecology 88:528-534. doi: 10.1046/j.1365-2745.2000.00473.x

Dickson TL, Hopwood JL, Wilsey BJ (2012) Do priority effects benefit invasive plants more than native plants? An experiment with six grassland species. Biological Invasions 14:2617-2624. doi:

$10.1007 / \mathrm{s} 10530-012-0257-2$

Ellenberg H (1974) Zeigerwerte der Gefäßpflanzen Mitteleuropas: Festband für Heinz Ellenberg. E. Goltze, Göttingen

Elton CS (1958) The Ecology of Invasions by Animals and Plants. Methuen and Co Ltd, London, UK

Fargione J, Brown CS, Tilman D (2003) Community assembly and invasion: an experimental test of neutral versus niche processes. Proceedings of the National Academy of Sciences of the United States of America 100:8916-8920. doi: 10.1073/pnas.1033107100

Ferenc V, Sheppard CS (2020) The stronger, the better - trait hierarchy is driving alien species interaction. Oikos 129:1455-1467. doi: 10.1111/oik.07338

Freckleton RP, Watkinson AR (2001) Asymmetric competition between plant species. Functional Ecology $15: 615-623$

Fukami T (2015) Historical contingency in community assembly: Integrating niches, species pools, and priority effects. Annual Review of Ecology, Evolution, and Systematics 46:1-23. doi: 10.1146/annurevecolsys-110411-160340

Fukami T, Martijn Bezemer T, Mortimer SR, Putten WH (2005) Species divergence and trait convergence in experimental plant community assembly. Ecology Letters 8:1283-1290. doi: 10.1111/j.14610248.2005.00829.x

Funk JL, Cleland EE, Suding KN, Zavaleta ES (2008) Restoration through reassembly: plant traits and invasion resistance. Trends in Ecology \& Evolution 23:695-703. doi: 10.1016/j.tree.2008.07.013

Funk JL, Parker IM, Matzek V, Flory SL, Aschehoug ET, D'Antonio CM, Dawson W, Thomson DM, Valliere J (2020) Keys to enhancing the value of invasion ecology research for management. Biological Invasions 22:2431-2445. doi: 10.1007/s10530-020-02267-9

Funk JL, Wolf AA (2016) Testing the trait-based community framework: Do functional traits predict competitive outcomes? Ecology 97:2206-2211. doi: 10.1002/ecy.1484

Gerhardt F, Collinge SK (2003) Exotic plant invasions of vernal pools in the Central Valley of California, USA. Journal of Biogeography 30:1043-1052. doi: 10.1046/j.1365-2699.2003.00911.x 
Gillhaussen P von, Rascher U, Jablonowski ND, Plückers C, Beierkuhnlein C, Temperton VM (2014) Priority effects of time of arrival of plant functional groups override sowing interval or density effects: a grassland experiment. PloS one 9:e86906. doi: 10.1371/journal.pone.0086906

Going BM, Hillerislambers J, Levine JM (2009) Abiotic and biotic resistance to grass invasion in serpentine annual plant communities. Oecologia 159:839-847. doi: 10.1007/s00442-008-1264-y

Goldstein LJ, Suding KN (2014) Applying competition theory to invasion: resource impacts indicate invasion mechanisms in California shrublands. Biological Invasions 16:191-203

Grime JP (1998) Benefits of plant diversity to ecosystems: Immediate, filter and founder effects. Journal of Ecology 86:902-910

Hess MCM, Buisson E, Fontes H, Bacon L, Sabatier F, Mesléard F (2020) Giving recipient communities a greater head start and including productive species boosts early resistance to invasion. Applied Vegetation Science 23:340-352. doi: 10.1111/avsc.12502

Hess MCM, Mesléard F, Buisson E (2019) Priority effects: Emerging principles for invasive plant species management. Ecological Engineering 127:48-57. doi: 10.1016/j.ecoleng.2018.11.011

Hood WG, Naiman RJ (2000) Vulnerability of riparian zones to invasion by exotic vascular plants. Plant Ecology 148:105-114. doi: 10.1023/A:1009800327334

Hooper DU, Chapin FS, Ewel JJ, Hector A, Inchausti P, Lavorel S, Lawton JH, Lodge DM, Loreau M, Naeem S, Schmid B, Setälä H, Symstad AJ, Vandermeer J, Wardle DA (2005) Effects of biodiversity on ecosystem functioning: A consensus of current knowledge. Ecological Monographs 75:3-35. doi: 10.1890/04-0922

Hufbauer RA, Rutschmann A, Serrate B, Vermeil de Conchard H, Facon B (2013) Role of propagule pressure in colonization success: disentangling the relative importance of demographic, genetic and habitat effects. Journal of Evolutionary Biology 26:1691-1699. doi: 10.1111/jeb.12167

Jentsch A, White P (2019) A theory of pulse dynamics and disturbance in ecology. Ecology 100:e02734. doi: $10.1002 /$ ecy. 2734

Johnstone IM (1986) Plant invasion windows: a time-based classification of invasion potential

\section{Figures}



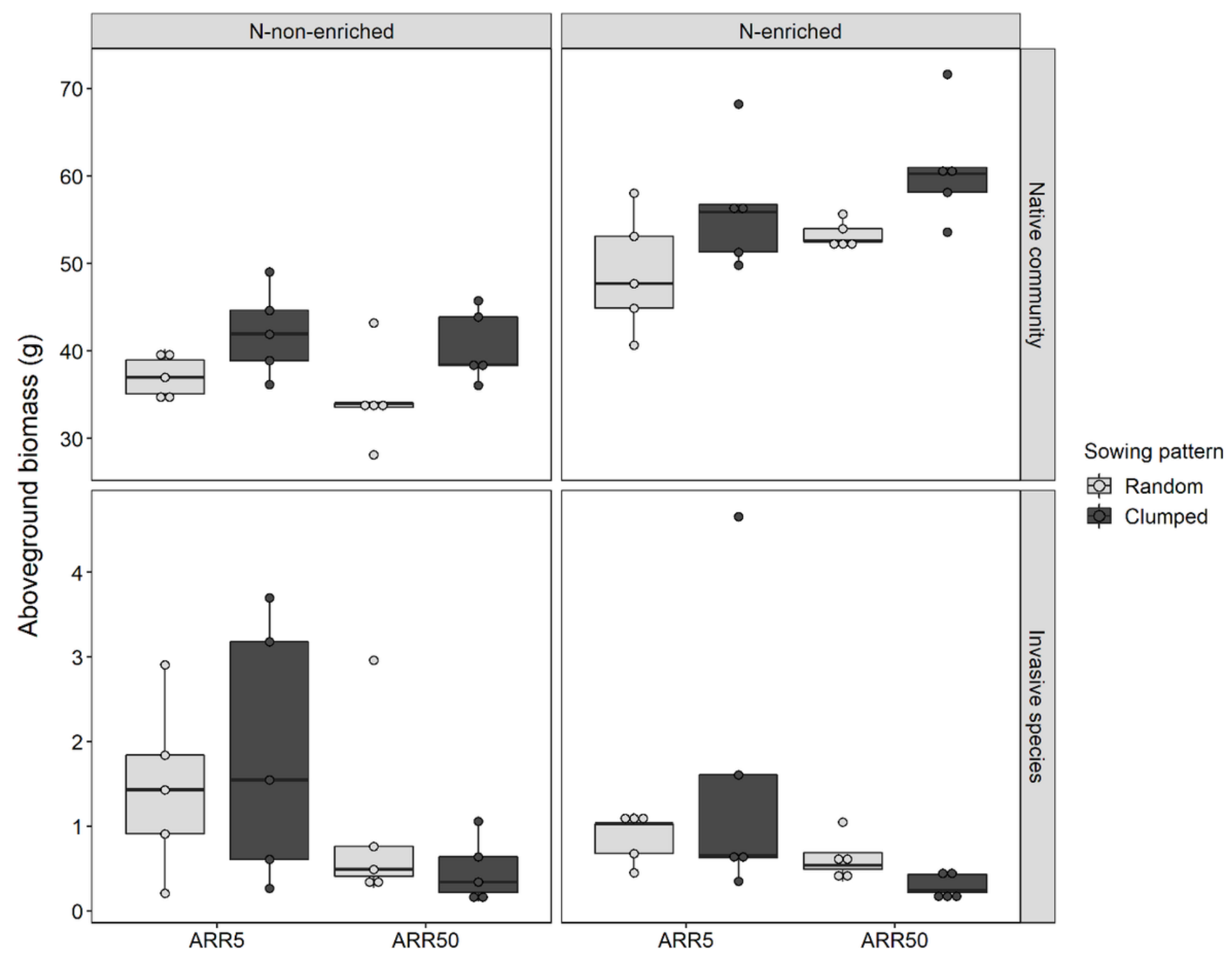

Figure 1

Effect of the community type, sowing pattern, and $\mathrm{N}$ fertilization on aboveground biomass of native grass mixtures (upper panel) and the invasive alien Solidago gigantea (lower panel), 16 weeks after sowing. The two communities (ARR5 and ARR50) had low vs. high competitive traits and were subjected to pulses of $\mathrm{N}$ fertilization, which had a positive effect on native biomass $(\mathrm{p}<0.001)$, albeit without differences among communities. Clumped sowing resulted in more native biomass $(p<0.001)$, and $S$. gigantea was significantly less productive in the high-competition community ARR50 

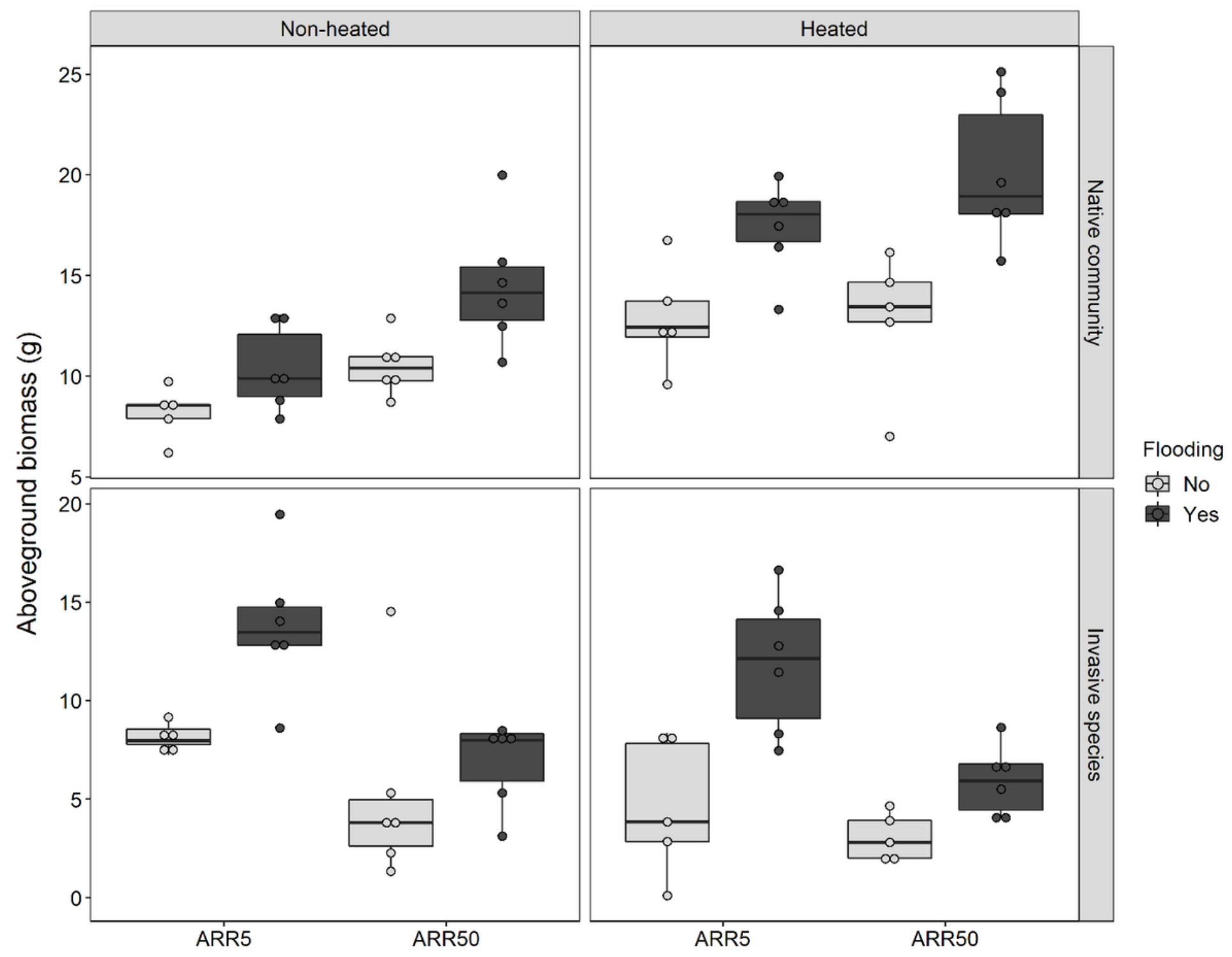

Figure 2

Effect of the community type, flood, and heat pulses on aboveground biomass of the two native communities (upper panel) and the invasive alien Solidago gigantea (lower panel), 14 weeks after sowing. The communities ARR5 and ARR50 were established based on trait hierarchies, and subjected to weekly interspersed pulses of heat and flood, that had a positive effect on the biomass of the two native communities $(p<0.001)$. Community ARR50 produced more native biomass $(p<0.05)$, and $S$. gigantea was significantly less abundant here, while more biomass was produced when the invaded communities experienced flood pulses $(p<0.001)$ 
A
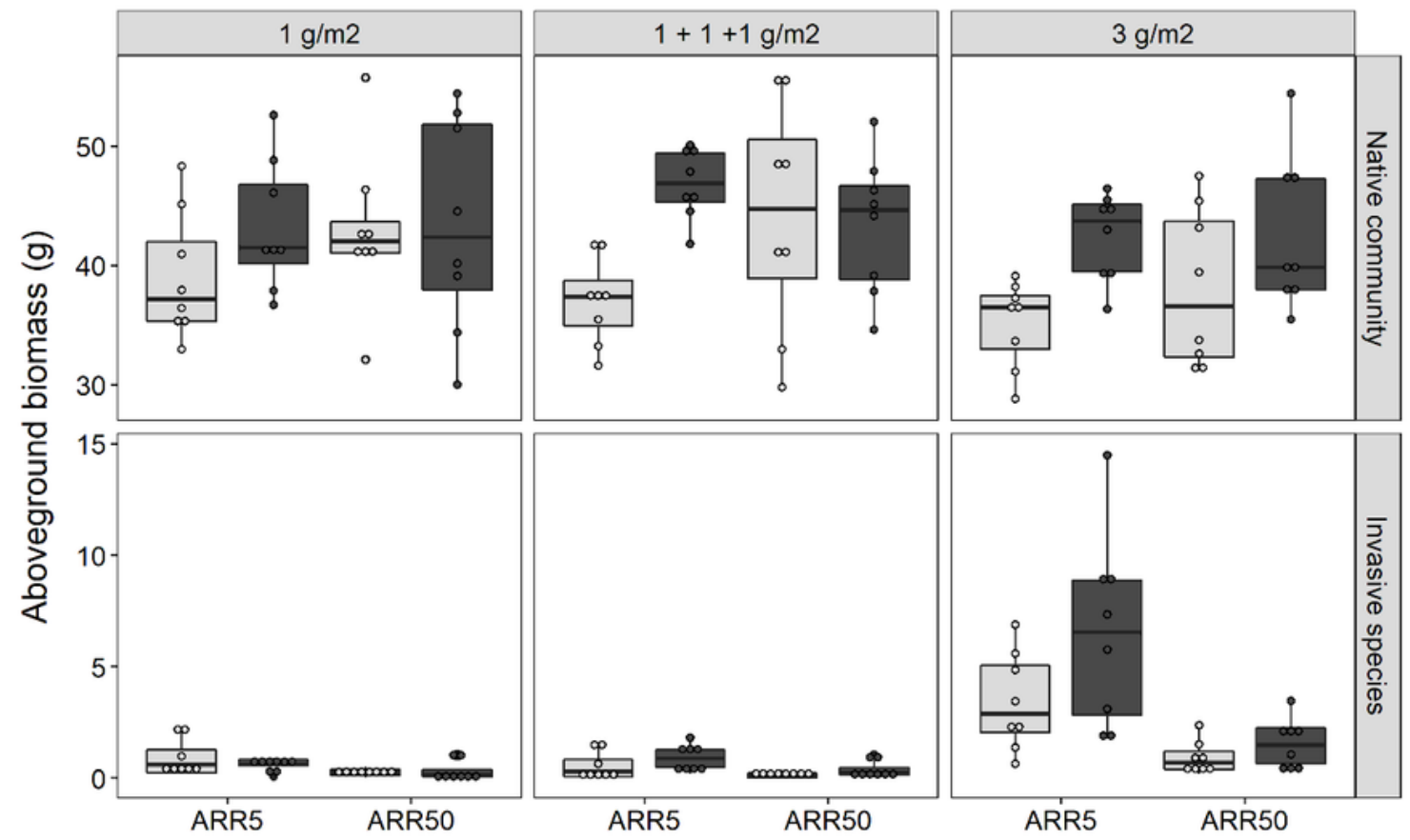

Flooding

安 No

Yes

B
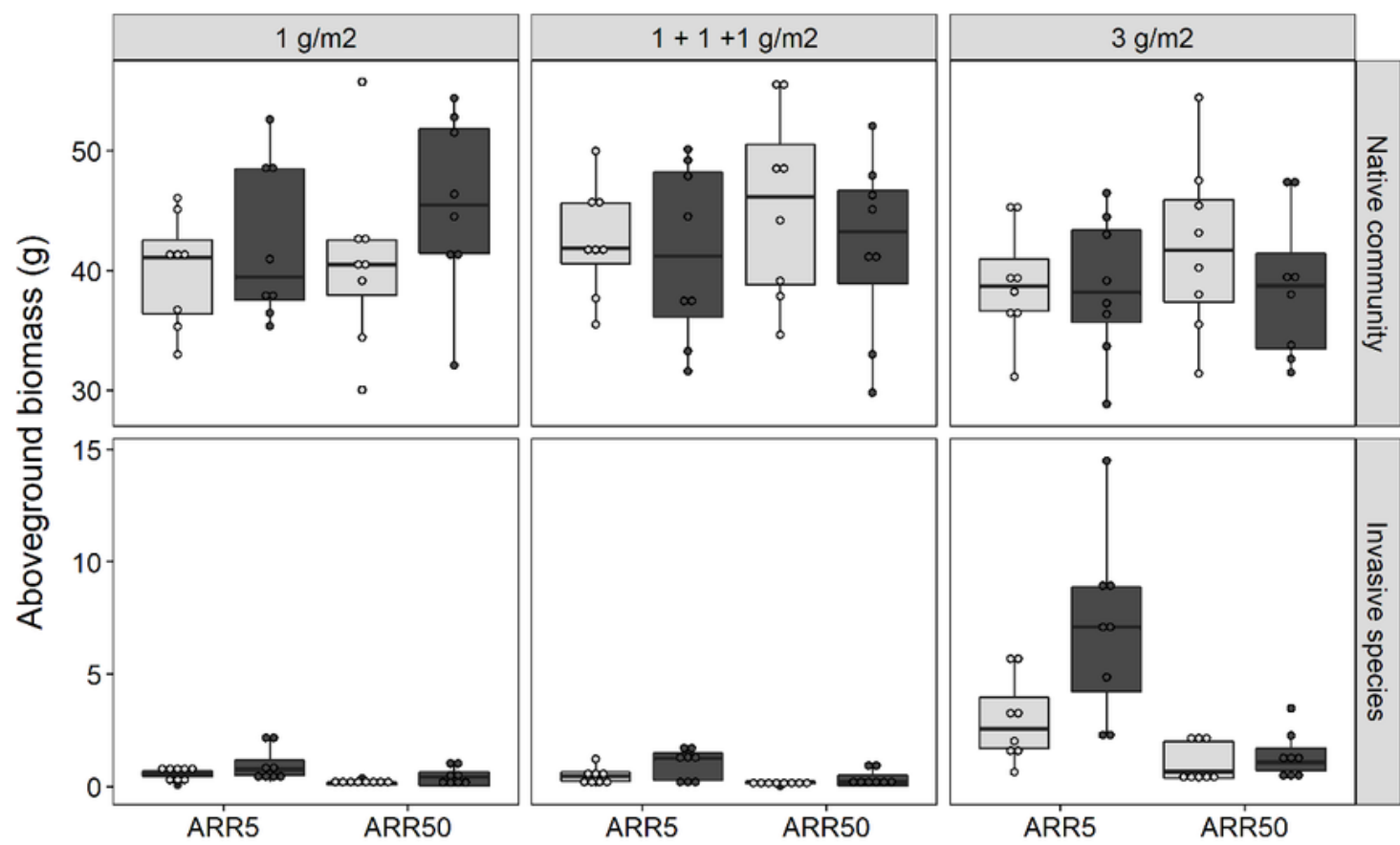

Heating

审 No
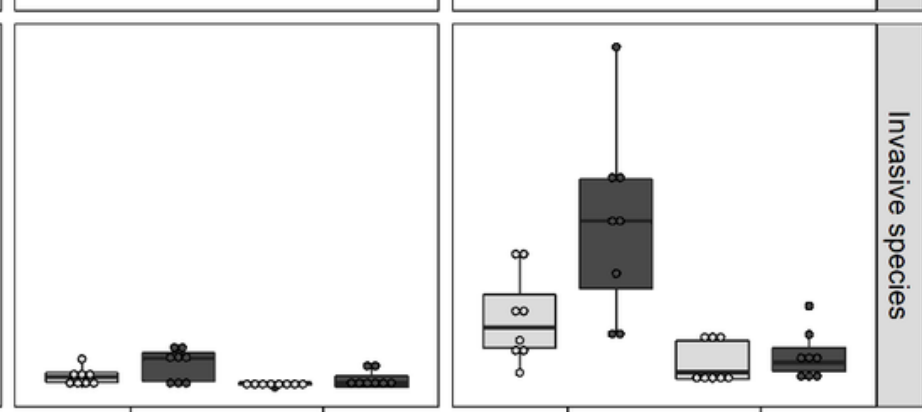

Yes

\section{Figure 3}

Effect of the community type and invasive propagule pressure on aboveground biomass of native grass communities (upper panel) and the invasive alien Solidago gigantea (lower panel), 17 weeks after sowing and subjected to flood (A) and heat (B) pulses. The two communities ARR5 and ARR50 were established based on trait hierarchies and sown with three different levels of invasive propagule pressure, i.e., $1 \mathrm{~g} \mathrm{~m}-2$ simultaneously with native sowing, $1+1+1 \mathrm{~g} \mathrm{~m}-2$ (three weekly introductions of $1 \mathrm{~g} \mathrm{~m}-2$ each), and $3 \mathrm{~g} \mathrm{~m}$ - 
2 simultaneously with native sowing. A large early added propagule had a negative effect on the biomass of the two native communities $(p<0.1)$. Community ARR50 affected negatively the biomass of $S$. gigantea $(p<0.01)$, while more invasive biomass was produced with an early added invasive propagule of $3 \mathrm{~g} \mathrm{~m}-2(\mathrm{p}<0.001)$

A

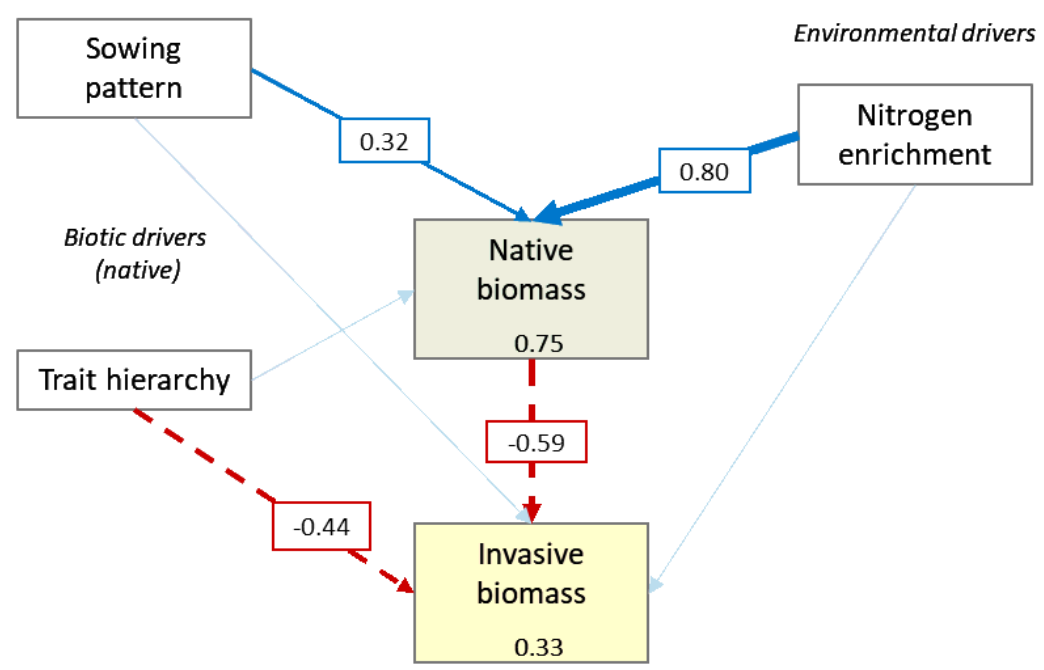

B

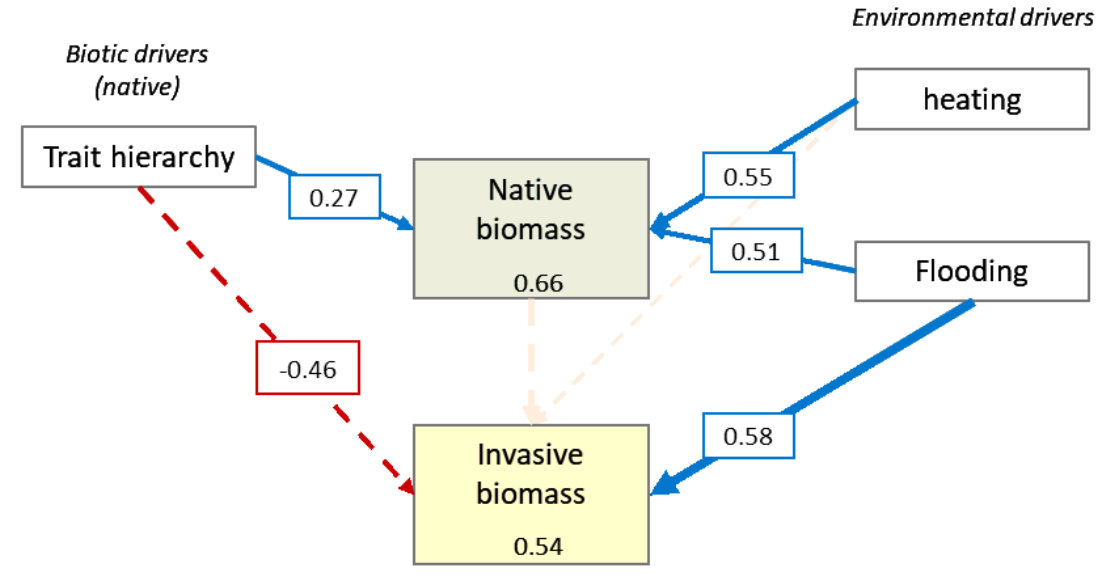

C

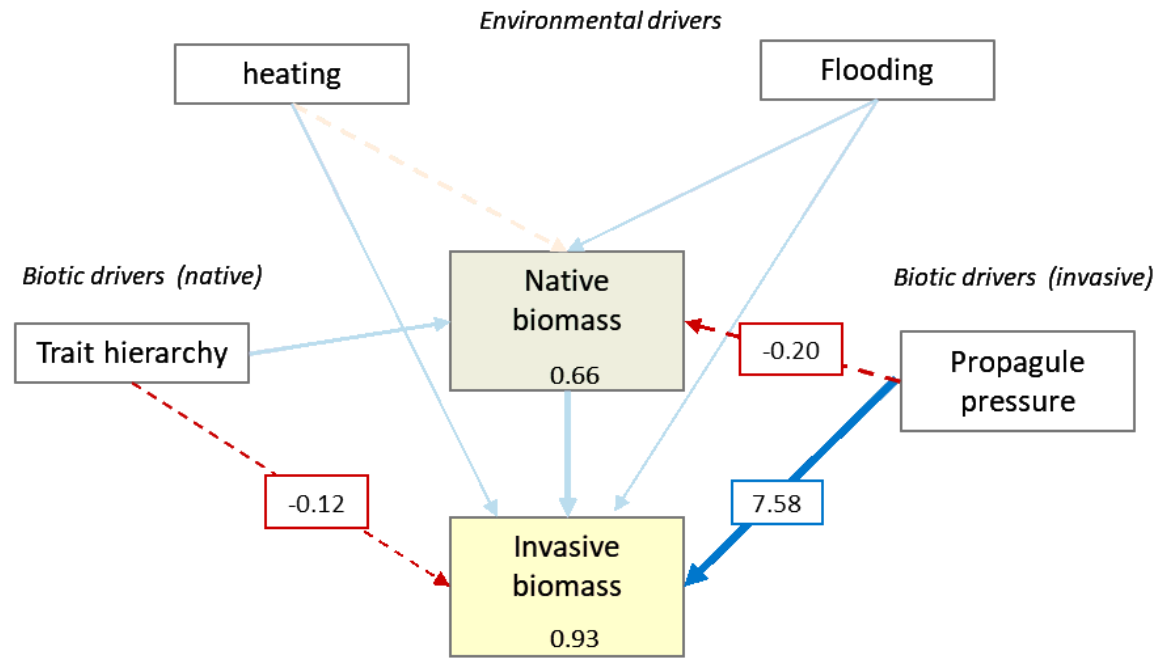

Figure 4 
Structural Equation Model fitted with standardized coefficients to test direct and indirect effects of (A) competitive traits, sowing pattern, and $\mathrm{N}$ enrichment, (B) competitive traits, and heat and flood pulses, and (C) competitive traits, propagule pressure, and heat and flood pulses, on aboveground biomass of the invasive Solidago gigantea and the native grass communities. Solid and dashed arrows indicate that the drivers had a significant positive or negative effect on biomass, respectively, while half-transparent arrows indicate no detectable influence of the driver $(p>0.05)$. Standardized coefficients are presented for each significant path; conditional R 2 values for the individual models are shown for each response variable

\section{Supplementary Files}

This is a list of supplementary files associated with this preprint. Click to download.

- RojasetalBiollnvSupplmaterial.docx 